\title{
Developing a New Integrated Model to improve the using of Classical Approach in Designing Management Information Systems
}

\author{
${ }^{1}$ Mohammad M M Abu Omar, ${ }^{2}$ Khairul Anuar Abdullah \\ Limkokwing University of Creative Technology \\ Malaysia
}

\begin{abstract}
Management information system (MIS) is used to solve management problems in the practical life, the designing and building of the management information systems is done by using one of the systems development methodologies. Classical approach is one of these methodologies which still suffer from some critical problems when it is used in designing and building the management information systems, it consumes more time and cost during its life cycle. This paper develops a new integrated model to minimize the classical approach life cycle in designing and building the management information systems in order to avoid the additional consume in time and cost.
\end{abstract}

Keywords-Management Information System; MIS; Systems Development Methodologies; Classical Approach; Information System Life Cycle; ISLC

\section{INTRODUCTION}

The classical approach or (traditional approach) includes the series of stages that are used in building the management information systems [9], these stages are known as classical approach life cycle or the information system life cycle (ISLC) of the classical approach. The work of classical approach always uses the all stages of its life cycle in building the management information systems (MIS's), but this paper develops and presents a new integrated model that leads in many cases to partially use of the classical approach life cycle stages, so this new integrated model will help in solving the classical approach problems which are consuming additional time and cost.

The classical approach life cycle stages are main five sequential steps which are:

1) Planning Stage: it is the first stage in the information system life cycle, the responsibilities of this stage are:

- Defining the problem and collecting the required information about the problem which the system will solve it.[1],[2]

- Determining the user's requirements, which the developed system will solve them. .[1],[2]

- Determining the estimated budget and time to accomplish the system.[1],[2]

- Suggesting a solution or list of solutions to the problem.[1],[2]
2) Analysis Stage: it is the second stage in the information system life cycle. In this stage the system analyzer will study each solution in the list of the suggested solutions that is obtained from the previous stage (planning stage) and then choose the best solution. [1],[2]

3) Design Stage: it is the third stage in the information system life cycle. Here, the designer's team will provide all the design necessary requirements such as: input screens, output screens, reports, database and system algorithms. [1] ,[2]

4) Development Stage: it is the fourth stage in the information system life cycle. Here the system will be programmed and operated. [1],[2]

5) Test and Maintenance Stage: it is the fifth (final) stage in the information system life cycle. Here, the system will be tested if it includes some errors or if it needs some improvements to be better and effective in achieving the users' requirements. [1],[2]

The weakness of the classical approach is coming from the permanent use of these all five stages in all cases; because there are many cases which actually need to use some of these stages not to all of them, so this research will solve these problems by developing the integrated model, which will organize the using of the classical approach in building the MIS's in order to solve the management problems.

\section{RESEARCH METHODOLOGIES}

The classical approach (traditional approach) life cycle consists sequential steps which makes this methodology simple, easy to use, and simple to implement in building the information systems [6], but at the same time, it still suffers from critical weakness; because of its additional consuming in time [6], which leads also to additional consuming in cost, so this research will help the classical approach to reduce from these problems, by the following research methodologies:

The first main methodology: is to develop a new classification for management problems.

The second main methodology: is to develop a new integrated model which will minimize the classical approach life cycle stages in many cases, this integrated model is designed according to the classification of the management problems in the first main methodology. 


\section{A. The first main methodology:}

This paper develops a new classification for the management problems; this classification has two main categories:

1) The first Category: in this category, the management problems are divided according to its nature and to its corresponding solutions, as in the following:

a) First order problem: the solution of this problem is clear, and it is usually one, you need only to collect the required information about this problem in order to implement it. So the solution for this type of problems will be defined as: direct solution. [2]

b) Second order problem: The solution of this problem is also clear, but it isn't determined by one solution, there are usually a list of multiple solutions. So the solution for this type of problems will be defined as: indirect solution. [2]
2) The second Category: in this category, the management problems are divided according to the type and nature of computer program (software) that will be used to solve these management problems. In this issue, the research divides the computer programs (software) which will be used by (MIS) in order to solve the management problems into two main types: [1]

a) First level problem: Here, the management problem needs software, which can be founded as s software package, and this means that management problem doesn't need to build and develop new software, but it needs software package which is ready software, that is available directly in the markets.[1]

b) Second level problem: In this case, management problem needs to build and develop its own special software, which (MIS) will use it to solve this problem. [1]

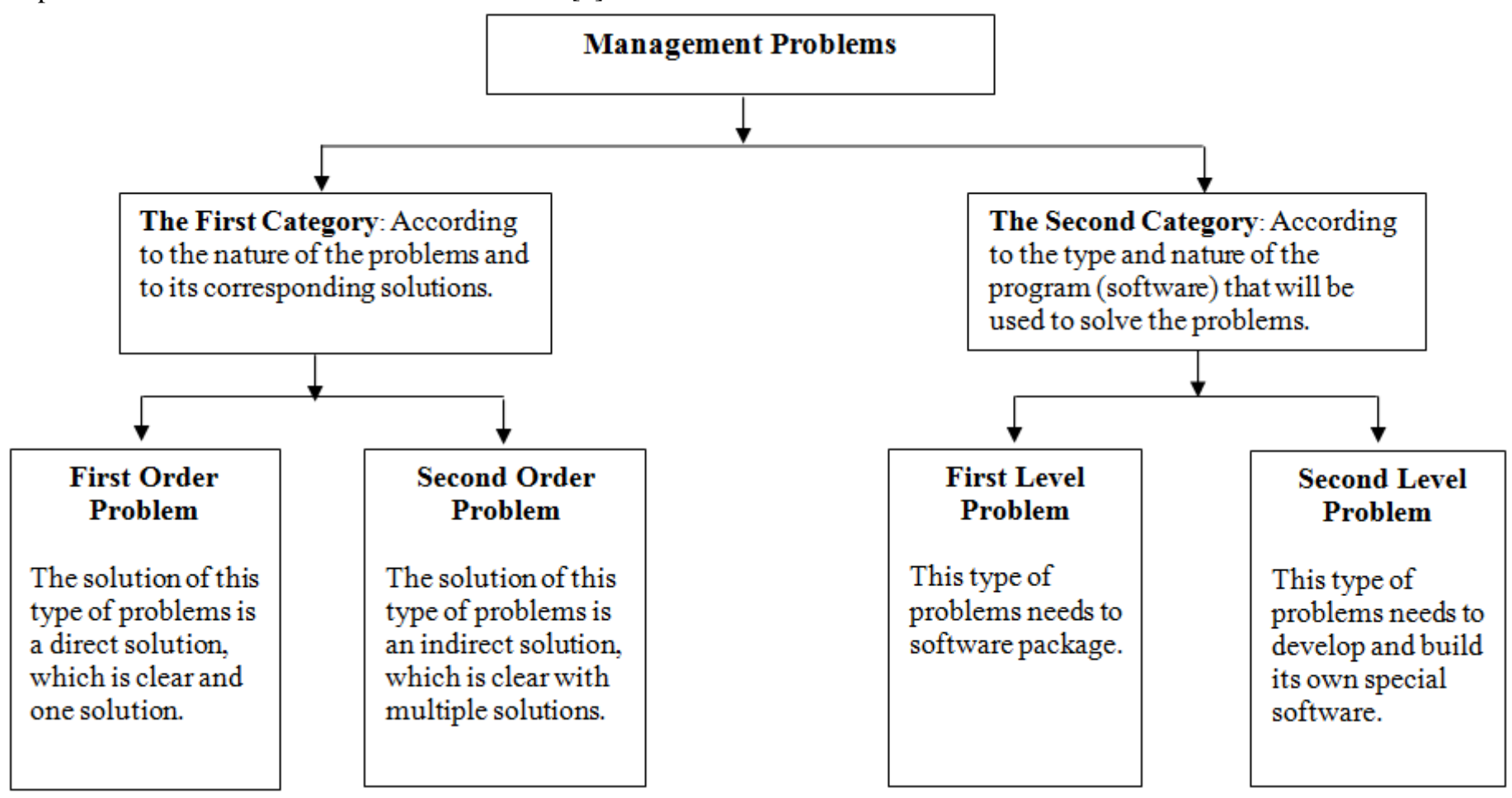

Fig. 1. The Research First Main Methodology

\section{B. The second main methodology:}

This research develops and introduces a new integrated model, in order to minimize the classical approach life cycle during the building of management information systems (MIS's), so this integrated model will help the classical approach to reduce the additional consuming in time and cost, and this will increase the efficiency of classical approach in building the MIS's.

The integrated model is developed step by step by finding sub approaches according to the management problems classification, which the research develops and introduces through the first main methodology in the previous section 2.1
1) Analysis the Effect of Management Problems Classification on the Information System Life Cycle (ISLC) of the Classical Approach:

The research will study the effect of each type of management problems on the information system life cycle (ISLC) which is a adopted by classical approach. The analysis will include all types of the management problems that are mentioned in section (2) through the management problems classification, which are: the first category (first order problem, second order problem) and the second category (first level problem, second level problem).

needed in this case, but also must be avoided, since if it is used, this will consume more time, effort and cost through 
using of the analysis stage, which the determined problem doesn't need, due to its nature and properties. [2]

a) Analysis the Effect of the First Order Management Problems on the ISLC of the Classical Approach:

The research defines the management problem as: first order management problem, when its solution is: direct solution; which is clear, and it is usually one, you need only to collect the required information about this problem in order to implement it.[2]

In this case, there is no need to find multiple solutions to the problem and choose the best solution. This means that there is no need to consume more time, effort and cost in using analysis stage, which is the second stage in the information system life cycle that is adopted by classical approach.[2]

Now, and according to the analysis of the effect of the first order management problem to the (ISLC) of the classical approach, the research develops the MIS approach (1) to build the management information systems which will be used to solve this type of problems. This approach (MIS New approach (1)) will avoid the using of analyses stage through building the management information system by using classical approach. Using this stage is not only
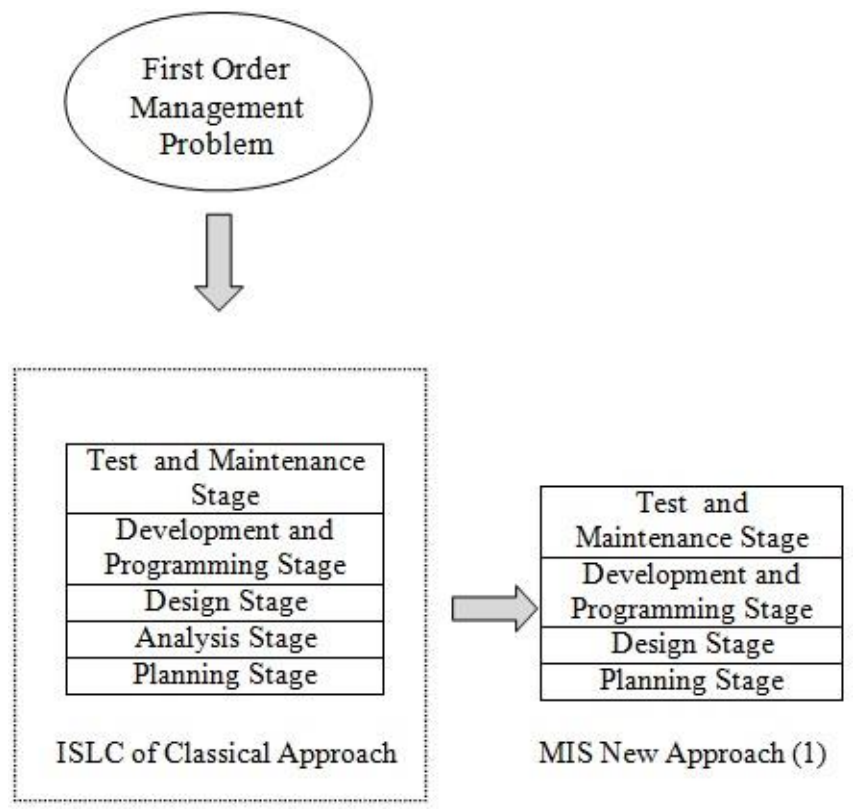

Fig. 2. Finding the MIS New Approach (1)

b) Analysis the Effect of the Second Order Management Problems on the ISLC of the Classical Approach:

The research defines the management problem as: second order management problem, when its solution is: indirect solution; there are usually list of multiple solutions for this type of problems, so this type of problems needs to clarify its solution by finding a list of the suggested solutions, then, the best solution will be chosen, and this will confirm the necessary of using the analysis stage, which is the second stage in the information system life cycle that is adopted by classical approach.[2]
The use of analysis stage in the ISLC of the classical approach will help these problems to change from second order management problem to be first order management problem.[2]

In this case, the research agrees with the current approach which classical approach uses in designing and building management information systems which includes all stages of information system life cycle (ISLC), and defines it as: MIS classical approach, so there is no skip to the second stage in the information system life cycle as in MIS approach (1), all stages must be used, this is because of the properties of this type of problems which are:

a- Solution of this type of problems is clear but it is an indirect solution; since it is not determined by one solution, on the contrary, there is a list of multiple solutions.

b- The existence of multiple solutions for this type of problems, will lead to the need to study each of these solutions in order to detect the best, this means that this type of problems needs ( analysis stage) which is the second stage in information system life cycle that is adopted by classical approach.[2]

\begin{tabular}{|c|}
\hline Test and Maintenance Stage \\
\hline Development and Programming Stage \\
\hline Design Stage \\
\hline Analysis Stage \\
\hline Planning Stage \\
\hline
\end{tabular}

Fig. 3. The MIS classical approach which uses all stages of classical approach

c) Analysis the Effect of the First Level Management Problems on the ISLC of the Classical Approach:

Here, management problem needs software, which can be founded as $\mathrm{s}$ software package, and this means that management problem doesn't need to build and develop new software, but it needs software package which is ready software, that is available directly in the markets. [1]

If we return to the information system life cycle that is adopted by classical approach, and which has been explained through the introduction in this paper, we will find that the building of the computer program (software), which the management information system (MIS) will use it to solve the management problems, is related directly with the third stage (Design Stage) in the information system life cycle, because the building of the computer program (software) includes already to the building of: algorithms, database, input and output screens, reports,....etc, and these are the responsibilities of the (Design Stage) in the information system life cycle.[1]

Hence, this research provides a scientific contribution which is: the building of computer program (software) will cause the need to use the design stage, and vice versa. So, if there isn't need to build a computer program (software), 
design stage in the information system life cycle will be skipped. [1]

Now, and according to the analysis of the first level management problems, the research develops a new approach (MIS New Approach (2)) to build the management information system (MIS) which will be used to solve this type of problems.[1]

The MIS new approach will skip the third stage (Design Stage) in the information system life cycle that is adopted by classical approach. this means that this new approach will minimize the information system life cycle to be four stages instead of five stages, and this will cause to reduce the number of employees that will work in the project team, in addition, the use of this new approach will help to save time, effort and cost, and this will lead to increase the efficiency in building and designing the management information systems by using classical approach.[1]

The MIS new approach will use the classical approach and skip the design stage (third stage) in building the management information system (MIS) which will be used to solve the first type of management problems. [1]

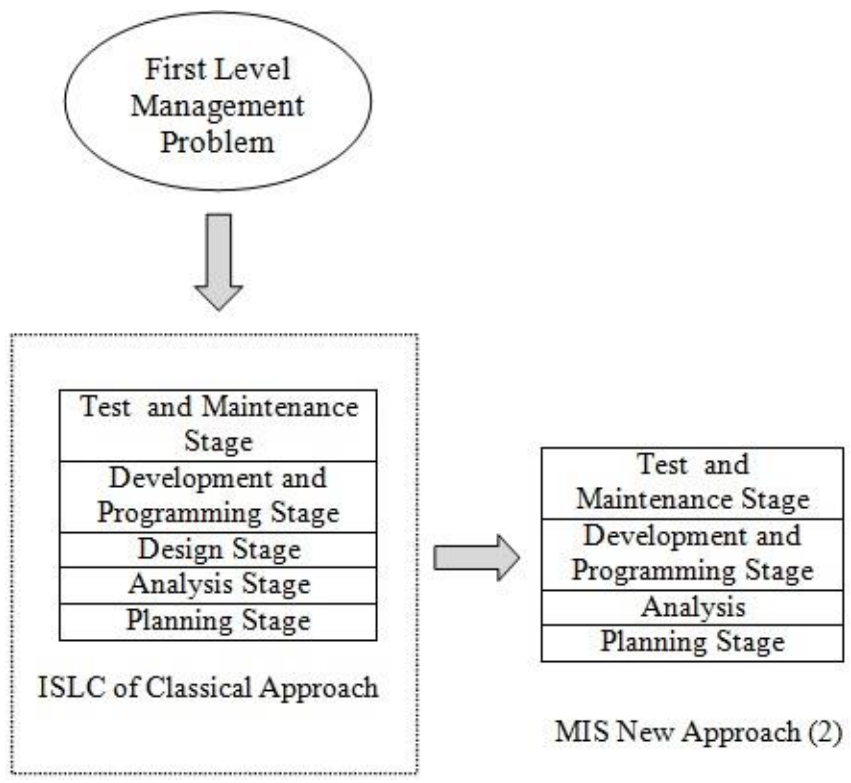

Fig. 4. Finding the MIS New Approach (2)

d) Analysis the Effect of the Second Level Management Problems on the ISLC of the Classical Approach:

In this case, the research agrees with the current approach which classical approach uses in designing and building management information systems, which includes all stages of information system life cycle, and defines it as: MIS classical approach, so in this case, there is no skip to the third stage (Design Stage) in the information system life cycle, as in MIS new approach(2); because and as it is mentioned in the section (2),this type of management problems needs to build its own special software, and this requires the use of design stage in the information system life cycle.[1]

\begin{tabular}{|c|}
\hline $\begin{array}{c}\text { Test and Maintenance } \\
\text { Stage }\end{array}$ \\
\hline Development and \\
Programming Stage \\
\hline Design Stage \\
\hline Analysis Stage \\
\hline Planning Stage \\
\hline
\end{tabular}

Fig. 5. The MIS classical approach which uses all stages of classical approach

\section{The COMbined MANAGEMENT PROBLEMS}

This research reaches to the new types of management problems and defines these problems as: (Combined Management Problems), these problems are appeared by the combination of two different problems from the problems that research defines them in the research methodology through two main categories which are: the first category (first order problem, second order problem) and the second category (first level problem, second level problem).

\section{A. Finding the Combined Management Problems:}

As it is mentioned in the previous section; the combined management problems are appeared by the combination of two different management problems which the research defines them in the research methodology, now we will number each one of these problems as mathematical equations numbering:

* First category

- First order management problem.

- Second order management problem......(1.b)

* Second Category.

- First level management problem.

- Second level management problem.......(2.b)

Now, we will apply the distributed operation between the previous equations:

(1) * (2)

Equation (X) implies that:

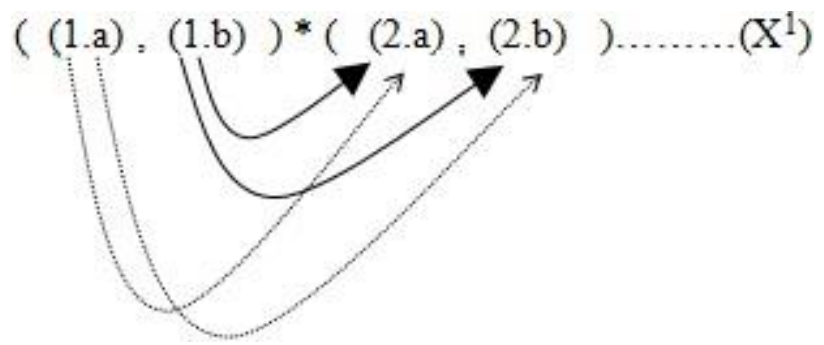

Now, we will list all the results probabilities which will be obtained from the applying of the distributive operation in equation $\left(\mathrm{X}^{1}\right)$ :

First probability: (1.a), (2.a)

Second probability: (1.a), (2.b)

Third probability: (1.b), (2.a)

Fourth probability: (1.b), (2.b)

The previous results will be interpreted, in order to find the new combined management problems: 
1) The first combined management problem:

It comes from the first previous probability $\{(1 . a),(2 . a)\}$, this means that the first combined management problem is a first order management problem and a first level management problem at the same time.

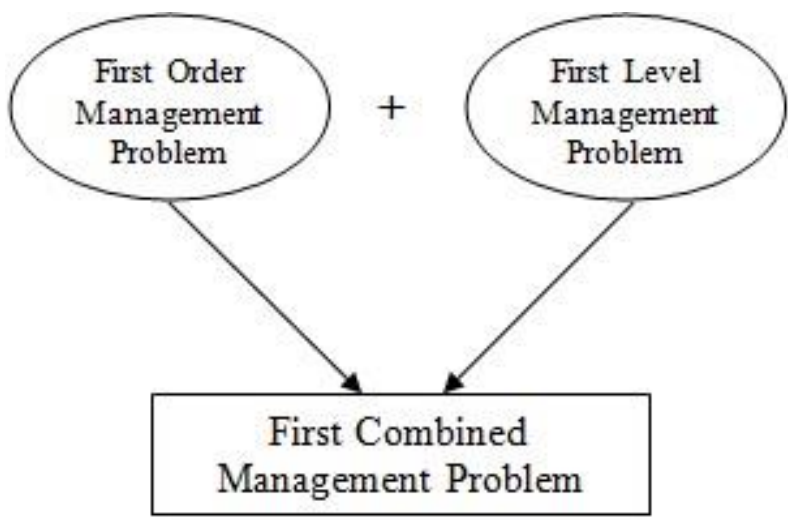

Fig. 6. First Combined Management Problem

and if we return to section 2.2 , we can note that the first order management problem leads to use the MIS new approach (1), which skips the analysis stage in the ISLC of the classical approach, on the other hand, the first level management problem leads to use the MIS new approach (2), which skips the design stage in the ISLC of classical approach, and thus, the first combined management problem will combine between the skipping of the two stages: analysis and design.

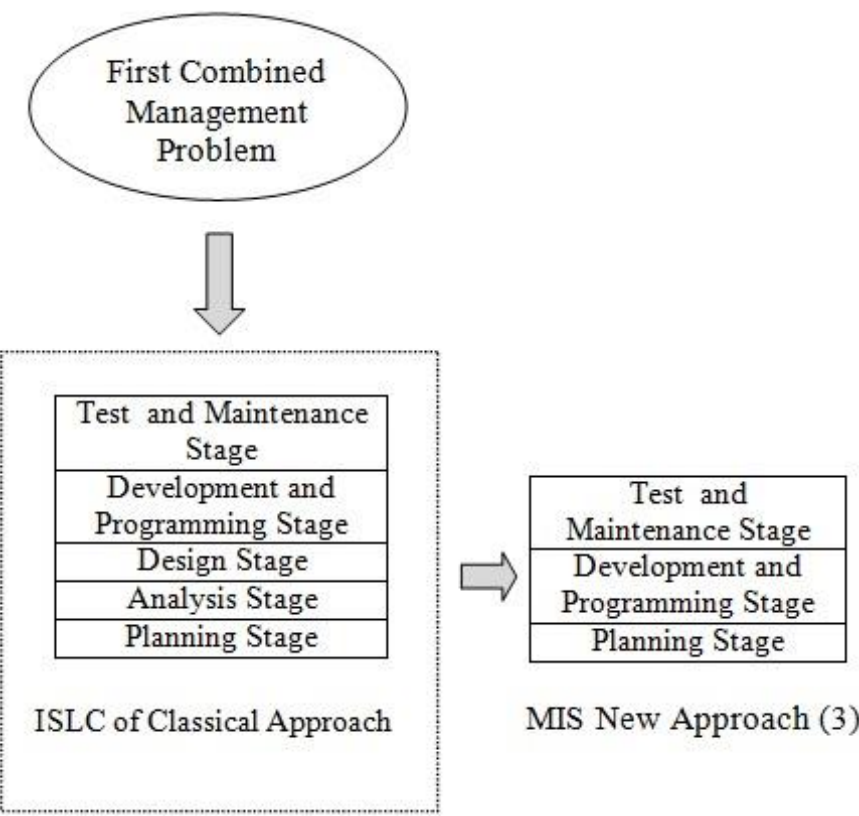

Fig. 7. Finding the MIS New Approach (3)

2) The second combined management problem:

It comes from the second probability $\{(1 . a),(2 . b)\}$, which means that the second combined management problem is a first order management problem and a second level management problem at the same time.

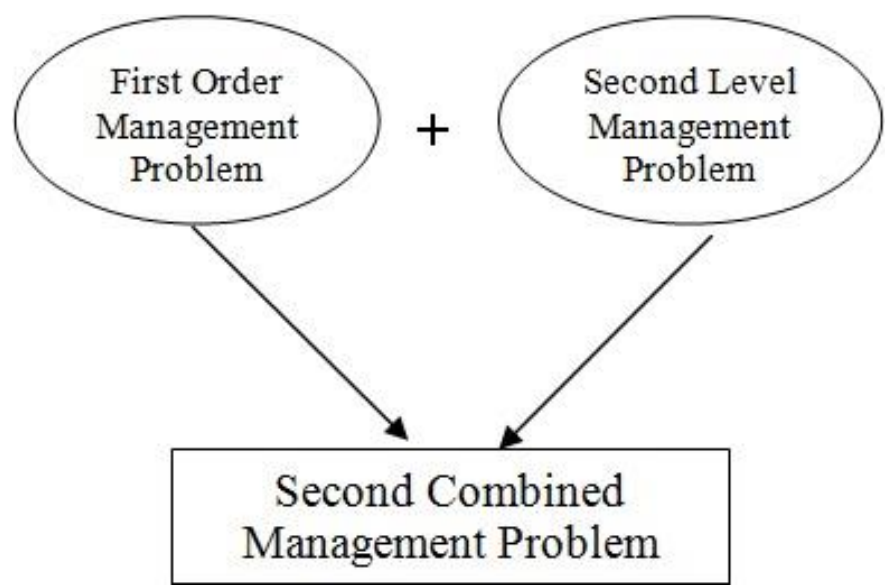

Fig. 8. Second Combined Management Problem

As the research has mentioned, the first order management problem leads to use the MIS new approach (1), which skips the analysis stage in the ISLC of the classical approach, but the second level management problem will use the current life cycle of the classical approach which uses all stages of the INSLC of the classical approach, so the second combined management problem will inherit only the skipping of the analysis stage, and hence, the second combined management problem will not generate a new approach to build the MIS, and instead of this, the research recommends to use the MIS new approach (1) to build the required MIS in order to solve the second combined management problem.
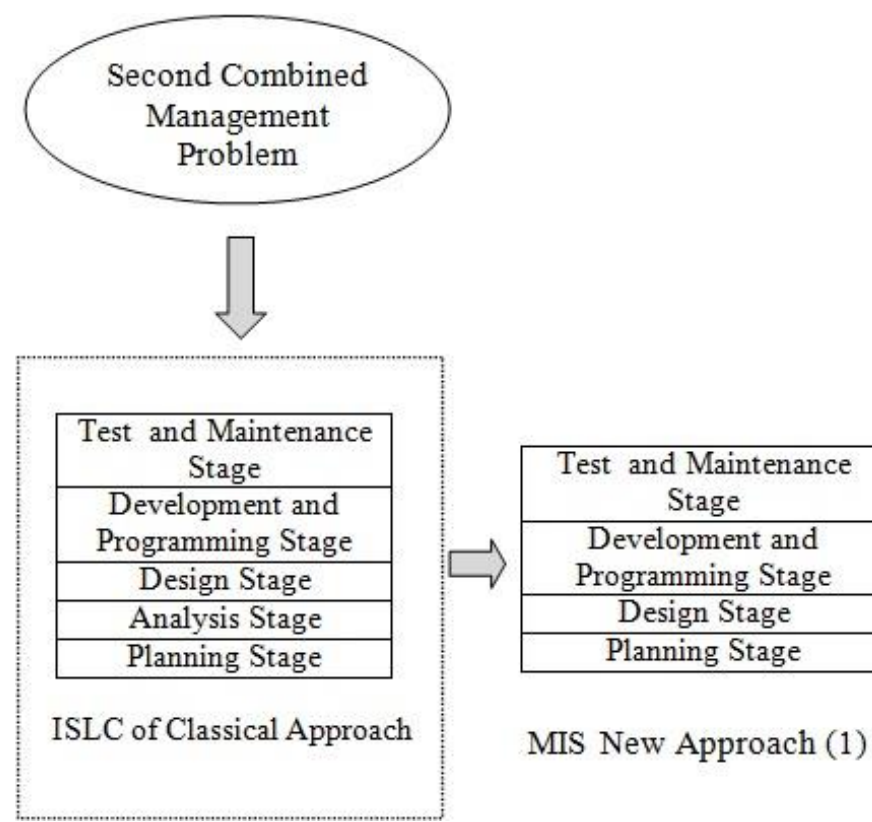

Fig. 9. Using the MIS New Approach (1) to Solve the Second Combined Management Problem

\section{3) The third combined management problem:}

It comes from the third probability $\{(1 . b),(2 . a)\}$, which means that the third combined management problem is a second order management problem and a first level management problem at the same time. 


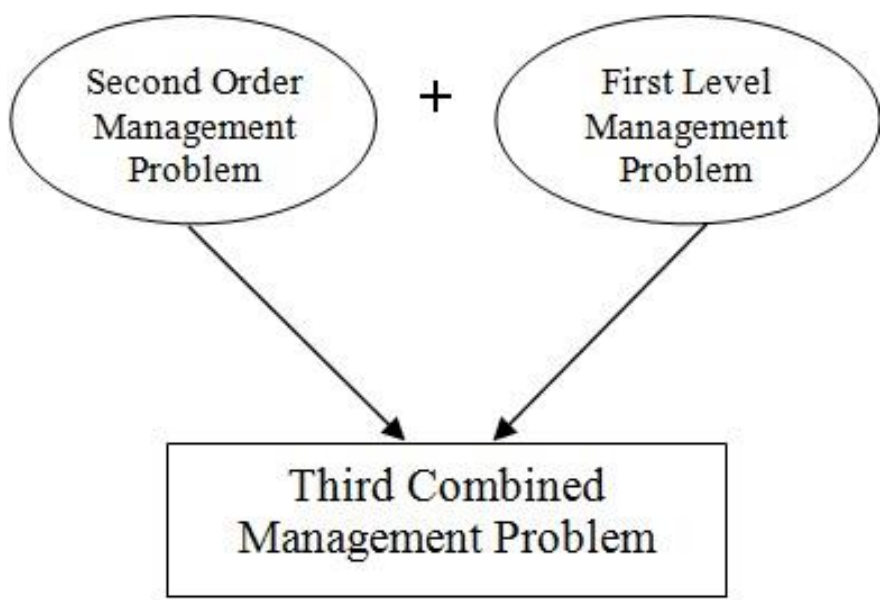

Fig. 10. Third Combined Management Problem

According to the research methodologies, the using of classical approach to build the MIS in order to solve the problems from the type of second order management problem, there is a need to use all stages of the ISLC of the classical approach, but the second level management problems lead to use the MIS new approach (2), which skips the design stage in the ISLC of classical approach, and thus, the third combined management problem will inherit only the skipping of the design stage, and this implies that the third combined management problem will not generate a new approach to build the MIS, and instead of this, the research recommends to use the MIS new approach (2) to build the required MIS in order to solve the third combined management problem.

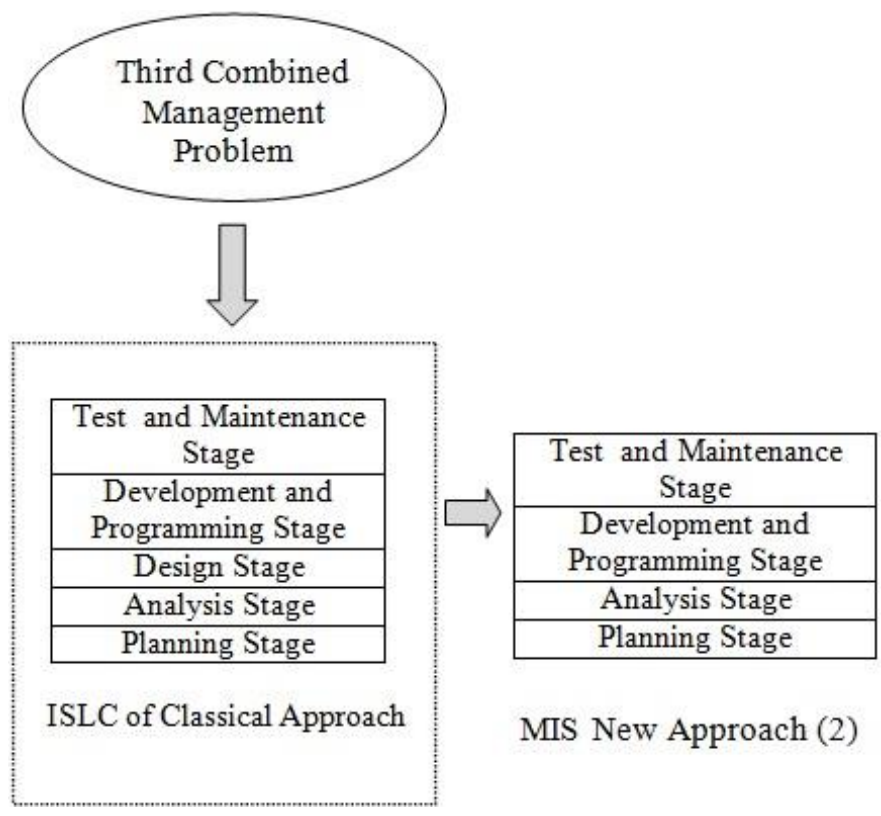

Fig. 11. Using the MIS New Approach (2) to Solve the Third Combined Management Problem

\section{4) The fourth combined management problem:}

This is the last one of the combined management problems, which comes from the fourth probability: $\{(1 . b)$, (2.b)\}, so the components of this problem are: the second order management problem and the second level management problem.

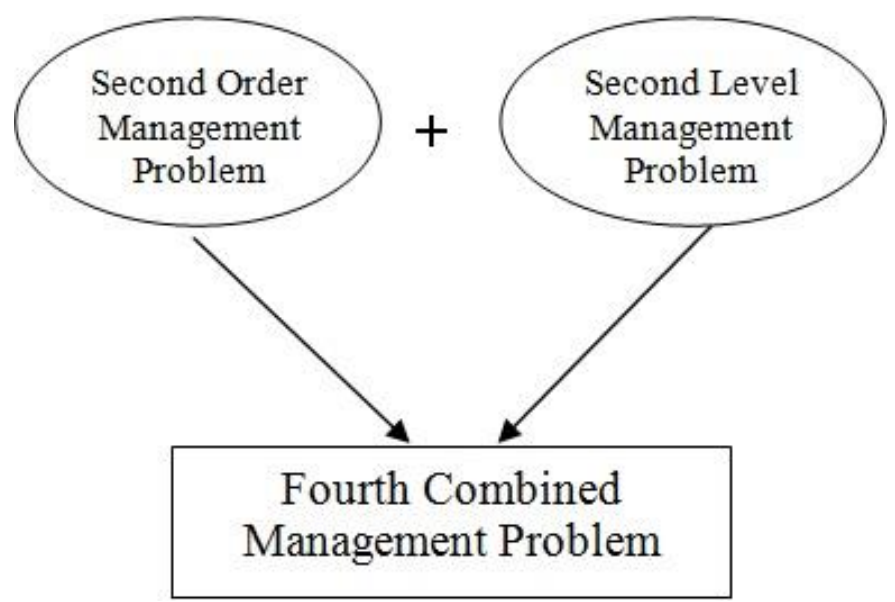

Fig. 12. Fourth Combined Management Problem

This research mentions in its methodologies to use the all stages in the ISLC of classical approach, when we want to solve the both two problems: second order management problem and second level management problem, which are the components of the fourth combined management problem, so building the MIS by using classical approach to solve the fourth combined management problem will lead to use the MIS classical approach which uses the all stages of the ISLC of classical approach, without any skipping to any stage.

\begin{tabular}{|c|}
\hline Test and Maintenance Stage \\
\hline Development and Programming Stage \\
\hline Design Stage \\
\hline Analysis Stage \\
\hline Planning Stage \\
\hline
\end{tabular}

Fig. 13. The MIS classical approach which uses all stages of classical approach to solve the fourth combined management problem

\section{THE NEWINTEGRATED MODEL TO BUILD AND DESIGN THE MIS BY USING CLASSICAL APPROACH}

Now, and after the finding of the sub approaches for solving the different management problems, these sub approaches will be the components of the new integrated model, so the research will combine all these sub approaches in order to build and find the new integrated model.

The new integrated model will implement a general and clear procedure in order to solve all types of the management problems which are defined and founded by this research; which provides suitable approaches to solve each one of these problems by using the classical approach.

The integrated model will increase the efficiency of the used of classical approach in building the required MIS that will be used to solve the management problems. Increasing the efficiency of the classical approach comes from the minimizing of the ISLC of the classical approach, in many different cases, which will help the classical approach to 
overcome to its problems by decreasing the additional consuming in time and cost.

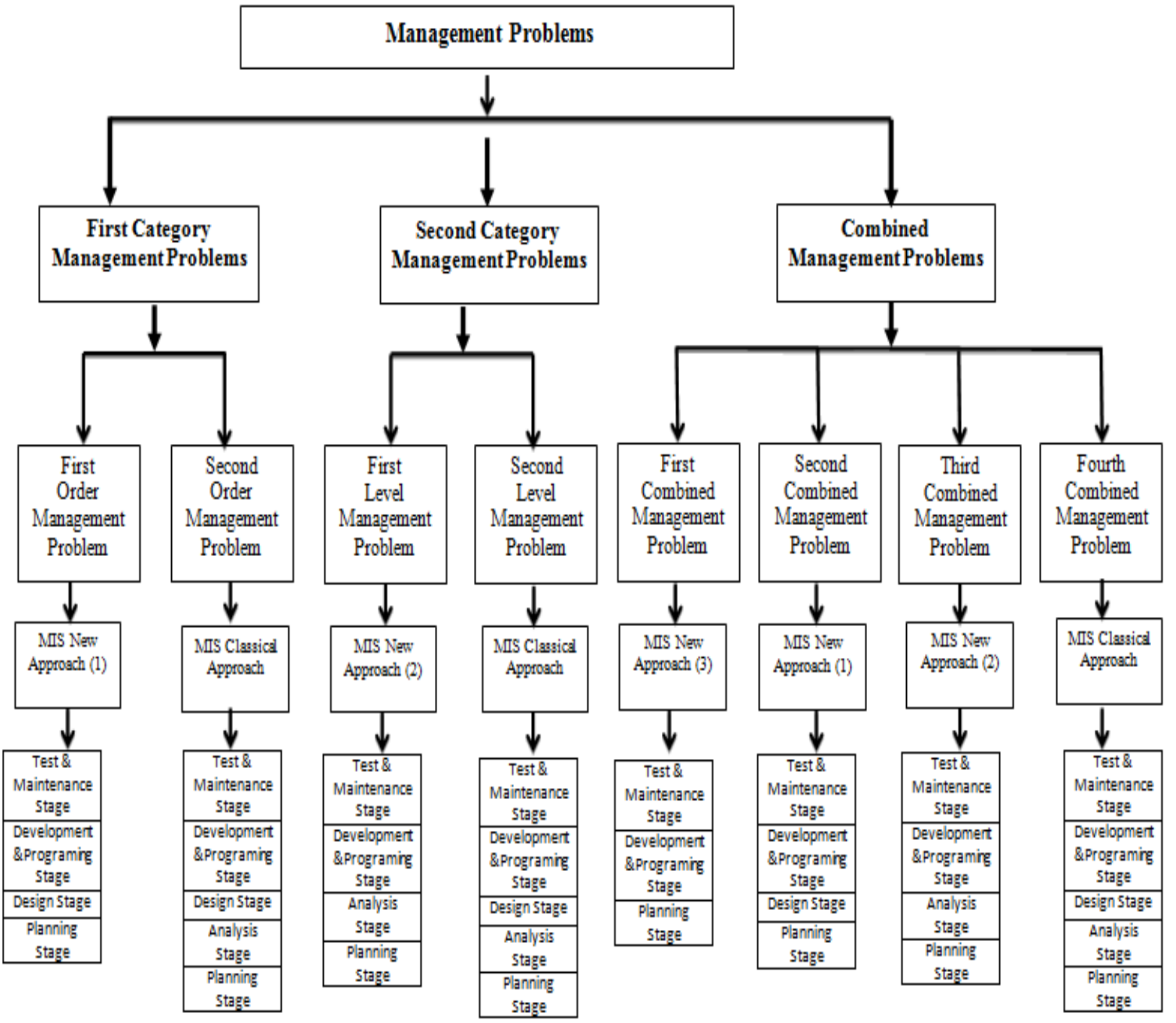

Fig. 14. The New Integrated Model

\section{CONCLUSION}

Classical approach is one of the information systems methodologies that is used to design and build the management information systems (MIS's). The classical approach suffers from critical problems; which are the long time and high cost in many different cases while building MIS. These problems come from the classical approach method, which always uses the all stages in its life cycle, although some of these stages are not necessary to be used in many different cases. In order to enhance the use of the classical approach in this field, the research develops a new classification and definition of the management problems that are probably solved by MIS, and also, some new sub approaches are developed from the classical approach in order to solve such management problems with partially use of the information system life cycle (ISLC) of the classical approach, the avoidance of the use of all stages of the ISLC will help the classical approach to save time and cost during building the MIS. And with a view to achieve a general, accurate and clear procedure that organizes the research methodologies in improving the use of classical approach in building the MIS's to solve the management problems, the research develops and implements a new integrated model which includes the developed classification of management problems and also all developed MIS sub approaches. 


\section{ACKNOWLEDGMENT}

I'd like to thank Professor Cedric D. Bell, the pro vice chancellor at Limkokwing University of Creative Technology, Malaysia, for the great help, guidance and encouragements to my $\mathrm{PhD}$ process, and my thanks also to all Limkokwing University staff.

\section{REFERENCES}

[1] Mohammad M M Abu Omar, " A New Approach to Increase the Efficiency of Classical Approach in Designing Management Information Systems(MIS's)", International Journal of Research in Computer and Communication Technology-IJRCCT, November 2014, Volume 3Issue11.

[2] Mohammed M M Abu Omar, " Developing New Methods in Designing Management Information Systems by Using Classical Approach to Solve Management Problems", International Journal of Computer Applications-IJCA, September 2014, Volume 101.

[3] Mathias Riechert, " Research Information Standardization as a Wicked Problem: Possible Consequences for the Standardization", In Proceedings of the International Conference of Current Research Information Systems, At Rome, 2014, Volume 12.

[4] Samson Yusuf Dauda, Jongsu Lee, "Technology adoption: A conjoint analysis of consumers' preference on future online banking services" Elsevier Journal of Information Systems, 2015, Volume 53.

[5] Ram L Kumar, Antonis C Stylianou, " A process model for analyzing and managing flexibility in information systems ", European Journal of Information Systems, 2013.

[6] Abubucker Samsudeen Shaffi , Mohaned Al-Obaidy "Analysis and Comparative Study of Traditional and Web Information Systems
Development Methodology (WISDM) Towards Web Development Applications" International Journal of Emerging Technology and Advanced Engineering-IJETAE, November,2013, Volume 3-Issue 11.

[7] Valdis Vizulis, Edgars Diebelis, "Self-Testing Approach and Testing Tools", Journal of University of Latvia, 2012, Volume 787.

[8] Lionel Briand, Yvan Labiche, "A UML-Based Approach to System Testing ", Journal of Carleton University, 2002, Version 4.

[9] Elizabeth Hardcastel, Business Information Systems, Ventus Publishing, 2008.

[10] Arthur M Langer, Analysis and Design of Information Systems, Springer, $3^{\text {rd }}$ Edition, 2008.

[11] Laudon, Kenneth C., and Laudon, Jane P., Management Information Systems, Prentice - Hall International, $9^{\text {th }}$ Edition, 2006.

[12] Laudon, Kenneth C., Essentials of Management Information Systems, Prentice -Hall International, $6^{\text {th }}$ Edition, 2005.

[13] Lejk, M. and Deeks, An Introduction to Systems Analysis Techniques, 2nd Ed., Pearson Education Limited, 2002.

[14] Satzinger, J., Systems Analysis and Design, $2^{\text {nd }}$ ed., Thomson Learning, 2002.

[15] Dennis, A. et al, Systems Analysis and Design: An- Object-Oriented Approach with UML, John Wiley \&Sons Inc., 2002.

[16] Maciaszek, A., Requirments Analysis and System Design, Developing Information Systems with UML, Addison-Wesley, 2001.

[17] Ricky W. Griffin, Management, 7th Edition, Houghton Mifflin, 2001.

[18] A. Ziya Aktas, Structured Analysis and Design of Information Systems, Prentice- Hall, 1987. 